\title{
2018: No Better Time to be a General Internist in Canada
}

In the early 1990s, when I was completing my residency training, general internal medicine in Canada was facing an existential crisis. From one direction, medical subspecialties were taking over as the preferred pathway for consultations from primary care physicians. A typical example was that a patient would be under the care of a cardiologist for their heart failure, an endocrinologist for their diabetes, and a nephrologist for their renal insufficiency. From the other direction, general internal medicine was being squeezed by the ascent of family medicine as a specialty in of itself, staking a greater claim to the generalist domain. As a PGY-4 in general internal medicine at the University of Toronto, I could count on one hand the number of faculty who called themselves general internists and there were even fewer trainees in this field. I distinctly recall one faculty member lamenting that he had received only one outpatient consultation request from a family physician - in the entire year! Early on in my career, when I was moonlighting as the in-house internist covering the busy emergency departments of large community hospitals, patients admitted to hospital would be siphoned off the next morning to the subspecialist closest to the admitting diagnosis and, if needed, other subspecialists were called in to help with secondary medical problems. Given these considerations, it was not surprising that general internal medicine was one of the least desirable destinations for residents completing their core internal medicine training. Indeed, the options for a career in general internal medicine were rather limited and included practicing in a remote geographic area, were sub-specialists were lacking, or pursuing a hospital-based academic career where the scope of practice reserved for general internists alone was rather narrow (e.g., staffing a perioperative consultation team).

If the early 1990s can be considered the nadir of general internal medicine in Canada, I am happy to say that the 2010s are a time where both the present is bright and future is even brighter. What has led to this phoenix-like transformation of general internal medicine? First, there was the formal recognition provided by the Royal College of Physicians and Surgeons of Canada in 2010 that general internal medicine was a bona fide subspecialty and the training requirements would be adjusted accordingly. Indeed, general internists possess the breadth of knowledge and expertise that would be lacking in other subspecialties and, unlike our primary care colleagues, have the depth in expertise for many common conditions like heart failure, chronic obstructive pulmonary disease, diabetes, renal and hepatic insufficiency to name a few. Second, the Royal College created diploma programs referred to as Areas of Focused Competence (or AFCs), became available, many of which could be entered through the pathway of general internal medicine. One the newest AFCs, which is close to my heart, is in Adult Thrombosis Medicine. This will commence recruiting trainees this year and, given its multi-organ involvement, will dovetail nicely with a practice in general internal medicine. Other AFCs available include Adults Hepatology, Transfusion Medicine, and Adult Solid Organ Transplantation. In 2018, general internists are well-positioned to craft their practice to include a more specialized area of expertise, whether through a formal AFC program or outside of this. Finally, and, perhaps, most importantly is the long overdue recognition of the value placed on general internists by hospitals, primary care facilities, and academic institutions.

It is gratifying, therefore, especially for many of us of an older vintage, to see general internal medicine being a career destination of choice. It is also gratifying to see in 2018 what many of us have known for decades: that general internal medicine provides a unique career path that combines subspecialty elements with the generalist ethos which we value so much. There is truly no better time to be a general internist in Canada.

DOI: 10.22374/cjgim.v13i3.315
James Douketis MD Editor-in-Chief

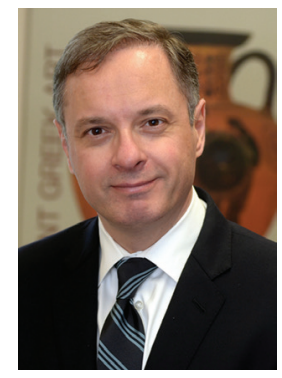

